\title{
INTELIGENCIA Y SUPERSTICIÓN EN BERGSON: LA FUNCIÓN FABULADORA
}

\begin{abstract}
Dr. Pablo Abraham Zunino*
Este artículo examina la noción de "función fabuladora" de acuerdo con la última obra de Henri Bergson: Las dos fuentes de la moral y de la religión (1932). Veremos que, en ese libro, el filósofo nos revela que la superstición surge como una especie de medida de precaución creada por la propia naturaleza contra los peligros que corre el ser humano, justamente por ser inteligente.
\end{abstract}

Palabras clave: Bergson, inteligencia, superstición, fabulación, religión.

\section{INTELLIGENCE AND SUPERSTITION IN BERGSON: THE MYTH- MAKING FUNCTION}

This article examines the notion of "myth-making function" according to the latest work of Henri Bergson: Two Sources of Morality and Religion (1932). We will see that, in this book, the philosopher tells us that superstition emerges as a kind of precaution created by nature itself against the dangers that could happen to human beings, just for being intelligent ones.

Keywords: Bergson, intelligence, superstition, fable, religion.

\footnotetext{
*Universidad de San Pablo, San Pablo, Brasil. Correo electrónico: zunino@usp.br
} 

$-$

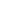




\section{Introducción}

El SER humANO SE CARACTERIZA, ENTRE OTRAS COSAS, POR HABER desarrollado su inteligencia al más alto grado. Las grandes creaciones humanas nos persuaden rápidamente de la superioridad del homo faber frente a los demás animales. Podemos admitir, tal vez, que la sobrevivencia del hombre en medio a la naturaleza fue posible gracias al poder de su inteligencia. Por otro lado, el hecho de haber superado (en parte) sus necesidades vitales, permitió al hombre contemporáneo usar la inteligencia en provecho de la especulación filosófica. Nuestro objetivo más amplio, por lo tanto, será comprender el alcance actual del lema bergsoniano: "Antes de filosofar, es preciso vivir"1. Contra los filósofos intelectualistas, que consideran el ejercicio del pensamiento una especie de placer - un lujo, escribe el autor en La evolución creadora (1907)-, defendemos la idea de que la inteligencia sirve primeramente para la acción y recién después puede considerarse en su aplicación filosófica, de carácter más especulativo. Por eso, si existe alguna "filosofía del hombre nocivilizado", ésta debe ser seguramente una filosofía practicada, antes de ser pensada, ya que forma parte de un conjunto de operaciones útiles para la vida.

Tendremos que despertar, entonces, al hombre primitivo que duerme en cada uno de nosotros, a fin de comprender mejor la necesidad vital que dio origen a esas convicciones originales que hoy consideramos "supersticiosas". Nuestra hipótesis de trabajo es que esas creencias se imponen históricamente por su vitalidad y no por lo que puedan tener de filosófico. Para verificarla, seguiremos el método de introspección que nos propone Bergson: a través de la "observación interior" es posible encontrar en sí mismo (hombre civilizado) la explicación de las creencias que atribuimos al hombre primitivo. Veremos que esas creencias no son, en realidad, necesariamente primitivas, sino que responden a una "tendencia de la vida" (interés vital). Pero como en el hombre primitivo aparecen más “infladas, exageradas y multiplicadas”, nos parecerá más fácil verificar lo que sucede aún en nosotros cuando adherimos a una creencia religiosa ${ }^{2}$.

1 Bergson, H., Les deux sources de la morale et de la religion, PUF, Paris, 1932, p. 173.

2 Ibid., pp. 170-171 
En efecto, uno de los errores más comunes de la filosofía de la religión es creer que existe un perfeccionamiento gradual, que va desde las creencias primitivas (en las fuerzas de la naturaleza, por ejemplo) hasta la etapa actual de adoración de un Dios único. Cometemos un error de ese tipo cada vez que nos preguntamos cómo pudo el hombre, siendo un ser inteligente, aceptar esas supersticiones tan absurdas que se encuentran en las religiones primitivas.

\section{El origen psicológico de la superstición}

Por eso, comenzaremos este artículo justamente con esa pregunta: ¿Cómo puede ser que seres tan inteligentes como nosotros (el hombre primitivo) hayan podido aceptar (y aún hoy sigamos aceptando) creencias y prácticas tan irracionales? Por lo menos, las consideramos dudosas: "la magia, el culto de espíritus o animales, el culto a los dioses, la mitología, supersticiones de todo tipo pueden parecer algo muy complejo si las tomamos una a una. Pero todo eso es muy simple", garantiza Bergson ${ }^{3}$.

Trataremos aquí de comprender el origen psicológico de la superstición a partir de la noción de fabulación, entendida como un acto de la mente que produce toda la serie de "representaciones fantasmales" que caracterizan a la superstición. Bergson nos ofrece una interpretación biológica de la sociabilidad y de la inteligencia humana en el contexto general de la evolución de la vida. Partimos de una necesidad biológica para encontrar la necesidad correspondiente en el ser humano ${ }^{4}$. Sin duda, el instinto real y activo es una necesidad biológica para los animales, pero en el hombre esa necesidad (humana) debe ser ocupada por una especie de instinto virtual o latente $^{5}$, lo que explica el surgimiento de una representación imaginativa y determina la conducta tal como lo haría el instinto natural en un animal ${ }^{6}$.

Estamos en condiciones de preguntar: ¿Cuál sería la necesidad que dio origen a la fabulación? Es cierto que la imaginación humana revela buena parte de su utilidad en la literatura (novelas, teatro) y en la mitología, pero la necesidad real (vital) que generó la función fabuladora tiene que ser algo más urgente: por qué no la religión? Nuestra estructura mental se desarrolló con esa capacidad creativa. Es decir que para enfrentar ciertos "peligros de la actividad intelectual", la inteligencia se habría dejado seducir por la superstición.

3 Ibid., p. 215.

4 El método de la biología nos enseña que para explicar una función debemos mostrar "cómo y por qué [esa función] es necesaria para la vida" (Ibid., p. 206).

5 Instinto virtual: "residuo del instinto que sobrevive en torno a la inteligencia y suscita seres imaginarios"; instinto "eclipsado" en el hombre, como si todavía quedase una tenue luminosidad alrededor de un núcleo, totalmente brillante, que es la inteligencia.

$6 \quad$ Ibid., p. 195. El concepto de "intención de la Naturaleza” retoma la metáfora del elán vital (cfr. La Evolución Creadora): el impulso de la naturaleza que dio origen al instinto en el animal, se extiende en el hombre como una tendencia natural (instinto virtual) que da lugar a esas "imágenes fantasmales" en el espíritu humano, como si la naturaleza le hubiese atribuido esa función a la religión. La necesidad natural (vital) de mantener los compromisos sociales responde a la intención de la vida de hacer que el hombre sea inteligente y sociable como otras especies. 


\section{La naturaleza y la inteligencia humana}

Retomemos nuevamente las dos preguntas que guían esta exposición: ¿Para qué sirve la función fabuladora? ¿De qué peligros la naturaleza quiso preservar a la inteligencia humana? Para responder esos interrogantes, Bergson establece una comparación entre la sociedad humana y una sociedad de insectos. Pensemos en una sociedad de hormigas o de abejas: son sociedades instintivas, evidentemente, porque se trata siempre de un organismo en el que los elementos existen en función del conjunto. En ese sentido, la colmena y el hormiguero poseen una cohesión social natural, tal como las células en los tejidos de un cuerpo. El caso de la sociedad humana es diferente, porque se trata de una sociedad inteligente, que deja tanta margen de libertad para los individuos que ya no sabemos si la sociedad fue hecha para ellos o si ellos fueron hechos para ella?.

Eso nos lleva a dar un segundo paso argumentativo, que consiste en reconocer que la fabulación responde a una doble función de la religión: Por un lado, la fabulación conserva la sociedad humana a través de la religión natural. El hombre no abandona completamente el instinto perdido, porque permanece en él en estado de virtualidad (instinto virtual). La función fabuladora sería un dispositivo natural capaz de enfrentar el trabajo intelectual. Sin ser más un instinto, desempeña en las sociedades humanas un papel simétrico al del instinto en las sociedades de insectos ${ }^{8}$. No obstante, la fabulación también precisa ser útil para el individuo. Así, el uso de la función fabuladora en beneficio propio supone que se puedan acumular y manipular ciertas fuerzas, tal como parece ser en el caso de la magia.

Pero la iniciativa individual puede comprometer la cohesión social, ya que el individuo siempre corre el riesgo de pensar sólo en sí mismo. Es natural que un ser inteligente se preocupe consigo, pensando en vivir mejor. En este sentido, la inteligencia conduce al egoísmo. Eso nos aproxima del primer punto de vista a partir del cual se puede comprender el surgimiento de la religión: "La religión es una reacción defensiva de la naturaleza contra el poder disolvente de la inteligencia" . Pensar significa "usar la capacidad intelectual en beneficio propio". Al pensar en sus cosas, el individuo comienza a disolver (deshacer) el tejido social. Era necesario enfrentar el peligro que la inteligencia representaba para sí misma: "un equilibrio natural opone la inteligencia a sí misma y de ahí surgen todas las representaciones intelectuales religiosas"10.

7 Asumimos aquí la hipótesis vitalista de Bergson, según la cual "lo social está en el fondo de lo vital [porque] la naturaleza se preocupa más con la sociedad que con el individuo” (p. 123). La creación de fábulas, por su utilidad, obedece a una mentalidad colectiva: el tabú, por ejemplo, era ventajoso para la especie, por lo tanto, racional (Ibid., p. 133)

8 De esa facultad de "alucinación voluntaria", todos tenemos un poco (en algún grado), pero se nota más en los niños y en los que saben apreciar la ficción, aunque también está presente en "los espectadores que lloran en el teatro" (Ibid., p. 206)

9 Ibid., pp. 134-135.

10 Ibid., pp. 134-135. 
Podemos formular ahora nuestros objetivos con más precisión. Examinar la religión primitiva nos permitirá, por un lado, identificar algunas ideas religiosas elementales; y por otro, comprender el trabajo de la función fabuladora en la práctica, o sea, a través de ejemplos concretos. Veremos que la fantasía humana produce variaciones en ciertos temas que nos provee la propia naturaleza y que de ahí podemos deducir las formas generales de la religión.

\section{La muerte}

La inteligencia no nos deja engañarnos: "El hombre sabe que va a morir"11. Y pensar en la muerte provoca desánimo, porque esa idea es "deprimente", contraria a la intención de la naturaleza (élan vital; movimiento de la vida). Para enfrentar la idea de que "la muerte es inevitable", nos apegamos a la idea contraria, o sea, a la imagen de una continuación de la vida después de la muerte ${ }^{12}$. A través de la función fabuladora, la inteligencia humana desarrolla una representación intelectual contraria y ese equilibrio natural neutraliza la idea a través de la imagen. En ese "juego de imágenes e ideas" estaría el origen de la religión. Eso nos conduce a un segundo punto de vista, según Bergson: "La religión es una reacción defensiva de la naturaleza contra la representación que hace la inteligencia de la inevitabilidad de la muerte"13.

Esta perspectiva nos muestra cómo trabaja la función fabuladora en la mentalidad del hombre. Algunas ideas se conjugan con otras, formando imágenes de nítida connotación religiosa. Detengámonos aquí para observar ese proceso en detalle. Para facilitar la exposición, dividimos la argumentación en tres etapas:

1) La primera idea que concibe el hombre al darse cuenta que va a morir es, probablemente, la de que el alma sobrevive al cuerpo. Pensemos en la imagen visual de un cuerpo, separada de su imagen táctil; conservemos sólo su "apariencia" que tomará la forma de una sombra o de un fantasma. De ahí la idea de un principio que anima el cuerpo: un soplo (anemos, viento) que después se espiritualizará en la idea de "alma humana" (anima) ${ }^{14}$.

2) La segunda idea implicada en este raciocinio es la de una reacción defensiva de la naturaleza. Para los primitivos, había una "fuerza" (maná) inherente al principio de la vida, que se puede acumular. Una tendencia natural (instinto virtual) nos hace pensar en el alma como una "sombra activa y poderosa" que sobrevive a la muerte del cuerpo.

3) Así, el hombre alimenta la idea de que los muertos se convierten en personajes con los que podemos contar. Del mismo modo que las fuerzas de la naturaleza, el espíritu de

11 Ibid., p. 135.

12 Cfr. Ibid., p. 136.

13 Ibid., p. 137.

14 Ibid., pp. 138-139. 
los muertos puede jugar a nuestro favor o en contra. Y la función fabuladora, estimulada por el miedo y la necesidad, da lugar a toda clase de ofrendas y prácticas ${ }^{15}$.

\section{El azar}

La muerte es un caso extremo, pero hay otros "accidentes menores" que afligen al hombre, porque la inteligencia nos sugiere todo el tiempo cuales son los mejores medios para realizar determinados fines, abriendo siempre una brecha donde se produce el accidente (hassard): un vacío, abierto al azar, que atrae lo inesperado. Llegamos de esta manera a un tercer punto de vista (azar/causalidad): Todas las representaciones religiosas son "reacciones defensivas de la naturaleza contra la representación que hace nuestra inteligencia de un margen desalentador de imprevisto entre la iniciativa tomada y el efecto deseado"16.

Todos conocemos la causalidad mecánica, ya que tenemos medios "racionales" para explicar las cosas como un enlace mecánico de causas y efectos. Pero cuando no conseguimos ayudarnos a nosotros mismos, recurrimos a una fuerza extra-mecánica como "causalidad secundaria"17. La superstición, según nos dice Bergson, proviene de nuestra propia "voluntad de triunfar", de esas ganas que sentimos por dentro de que todo salga bien. Nuestro deseo se exterioriza en el intento de eliminar (o disminuir) la distancia entre la decisión tomada y el resultado esperado, neutralizando el azar (lo accidental). No importa si el hombre es salvaje o civilizado, afirma nuestro autor: para saber lo que piensa un hombre es mejor prestar atención a lo que hace y no a lo que dice. Tomemos, como ejemplo, la (buena) "suerte" en el juego; el gesto del jugador que trata de detener la bola de la ruleta cuando pasa por el número que él apostó. Es esta fuerza la que denota una "voluntad de tener éxito" y establece una semejanza entre la mentalidad del civilizado y la del primitivo, sobre todo con respecto a la muerte, la enfermedad y el accidente ${ }^{18}$. La diferencia es que el hombre primitivo no cree en el azar: para él, nada ocurre porque sí, porque tuvo buena o mala suerte, sino porque alguna "fuerza activa" está presente. Por eso se siente víctima del hechizo de una bruja y se protege con amuletos. Ahora, si nosotros (hombres civilizados) usamos la palabra azar para explicar las cosas en fun-

15 Ibid., p. 142. Existen dos tipos de sociedades primitivas: (a) las que progresaron, quizás después de seguir un iniciador, un inventor, un hombre superior; (b) las que se conservaron, multiplicando lo que ya tenían. A través de la repetición y la exageración, lo que era irracional se convierte en absurdo (Ibid., p. 143) - lógica del absurdo: la mente va cada vez más lejos, perdiendo de vista su punto de partida. Bergson cita como ejemplo esas familias que mantienen actitudes extrañas (bizarres), fobias o supersticiones, sin hacer otro esfuerzo a no ser dejarse llevar por ellas. Noción de "apertura": sociedades primitivas que se encerraron en sí mismas, en vez de "abrir las ventanas" (ventilar, cambiar de aire). Les faltó ese esfuerzo para "ampliar sus horizontes". La superstición prospera en sociedades cerradas, así como hongos y bacterias lo hacen en ambientes cerrados.

16 Ibid., p. 146.

17 Ibid., p. 147.

18 La noción de mala suerte refuerza esa semejanza entre la inteligencia espontánea (ejemplo del soldado civilizado) y la mentalidad primitiva. Para Bergson, no difieren mucho una de la otra (Ibid., p. 153). 
ción de la suerte (buena o mala), es porque eso tiene un significado importante aún para nosotros $^{19}$.

\section{El miedo}

El hombre siempre tuvo miedo de lo imprevisible; en cualquier momento, puede ser sorprendido por un terremoto, una inundación, un tsunami: "la emoción del hombre frente a la naturaleza debe haber sido una de las causas de la religión, pero la religión surge menos del miedo que como una reacción contra el miedo" ${ }^{20}$. Ciertas entidades pueden asumir un antropomorfismo parcial cuando aún no tienen una personalidad completa, pero si una “intención" 21 . La creencia en esos casos se caracteriza más por la "confianza" que por el "miedo": es una garantía que nos da seguridad para afrontar y superar el miedo. Se trata, por lo tanto, de una emoción útil, un mecanismo psicológico creado por la naturaleza para preservarnos en aquellos casos que podemos hacer mucho más que dejarnos llevar por las circunstancias $^{22}$. La analogía con la fabulación es evidente, ya que también se trata de una reacción defensiva de la naturaleza que denota cierta utilidad.

\section{La magia}

Tal vez sea una de las creencias primitivas que más lejos se dejó llevar por la superstición. Pero, al profundizar nuestro análisis sobre la función fabuladora, descubrimos que hay dos elementos que caracterizan el surgimiento de la magia:

1. El deseo de controlar algo (o alguien), aunque estemos distantes (eso establece desde luego una semejanza entre la magia y la ciencia $)^{23}$.

19 Sobre las “causas místicas” (Ibid., p. 151). ¿Cómo puede el hombre primitivo explicar la muerte, la enfermedad y otros accidentes, apelando para una causa mística? ¿Cómo se explica, por ejemplo, que alguien sea golpeado por una roca en medio de una tormenta? Además de las causas mecánicas (viento, etc.), habría un "significado humano", porque ese hecho tiene una importancia significativa para cierto hombre. ¿Por qué me pasa esto a mí, y no a otros? Es como si, detrás del evento, hubiese una intención (positiva o negativa), que es lo que el hombre primitivo atribuye a una bruja o a la voluntad de un espíritu.

20 Ibid., p. 160.

21 Sobre esto, ver los comentarios de Bergson acerca de la "personificación" del terremoto por William James: (1) Contra la comprensión científica del terremoto (representación intelectual) se produce una reacción defensiva; (2) El miedo es proporcional a la gravedad del peligro: es inhibidor, paralizante, "una reacción defensiva de la naturaleza se produce contra una emoción también natural" (Ibid., p. 164); (3) La inteligencia, dirigida por el instinto virtual, llama la imagen que más la tranquiliza (le da más seguridad). Eso permite que el "hecho" tenga una unidad, una individualidad y sea también algo sociable y humano.

22 Paso de lo abstracto a lo concreto: una cosa es saber qué hacer en caso de accidente (incendio, por ejemplo), y otra muy distinta es estar en el lugar del incendio y actuar con frialdad, sin verse paralizado por el miedo, ni ceder a la desesperación de la situación. Noción de "instinto intelectual”: ante la representación inteligente de un accidente horrible, la naturaleza crea entre nosotros y el hecho simplificado (personificado en intención elementar) una "simpatía" que nos deja más relajados y así nos predispone a cumplir nuestro deber (Ibid., p. 167).

23 "La magia es un preludio a la ciencia" (Ibid., p. 178): sobre la semejanza entre los principios mágicos y los principios lógicos. 
2. La idea de que las cosas están cargadas (o se dejan cargar) de un fluido humano (aquí importa resaltar la relación entre magia y religión).

Bergson recusa la idea de un progreso continuo, que va de la magia a la religión y a la ciencia, cada una corrigiendo la anterior ${ }^{24}$. Para él, la diferencia entre magia y religión sería una diferencia de grado en el uso de la función fabuladora: la magia trabaja con entidades imprecisas (fuerzas, fantasmas o espíritus), mientras la religión da culto a dioses y divinidades.

Eso se opone también a la teoría sociológica dominante, según la cual la magia deriva de la religión. Al contrario, Bergson sustenta que "la religión comienza por la magia", porque las divinidades más definidas (dioses) sólo pueden surgir después de las entidades imprecisas (fuerzas) en el orden de la acción. La magia responde a un objetivo primitivamente práctico, del cual la religión desarrolla la parte teórica. De hecho, parece poco probable que el hombre primitivo haya pensado primero (a priori) en la representación del maná y que la magia haya surgido de esa idea. Más bien, como el hombre creía en la magia, porque ya la practicaba, debe haber representado las cosas de esa manera para explicar el éxito de sus prácticas mágicas ${ }^{25}$.

La magia y la religión son diferentes, pero tienen un origen común, por eso hay algo de magia en la religión y algo de religión en la magia: "Existe una magia natural, muy simple, que se reduce a un pequeño número de prácticas. Pero la reflexión sobre esas prácticas (o tal vez sólo su traducción en palabras) hizo que se multipliquen y se llenen de superstición, pues la fórmula va más allá del hecho que expresa"26.

\section{Conclusión}

Todo esto responde, en parte, a nuestra pregunta inicial: ¿Por qué el hombre, siendo inteligente, pudo aceptar religiones absurdas y todavía cree en supersticiones? Pero, en realidad, esa pregunta está mal formulada, porque desconsidera el proceso que dio origen a las creencias. El tratamiento estático (intelectual) solidifica el dinamismo (vital) y desvincula el conocimiento de la acción, perdiendo de vista lo que motivó el desarrollo primitivo de las religiones. Ahí está la diferencia entre filosofía y religión: una es pensamiento (especulación teórica); otra es acción (vivida en la práctica) ${ }^{27}$.

El problema de la inteligencia humana se coloca para la naturaleza de la siguiente manera: Cómo hacer que el hombre se apegue a la vida, a pesar de los peligros que lo acom-

24 Cfr. Frazer, J. G., Le Rameau d'or - Une étude sur la magie et la religión, Reinwald, Paris, 1903.

25 Bergson, H., op. cit., p. 174.

26 Ibid., p. 178.

27 Ibid., p. 215. 
pañan por su inteligencia? Vimos que la inteligencia representa una doble amenaza para el propio hombre. Por un lado, la inteligencia nos da la conciencia de la muerte y la incertidumbre sobre el resultado de nuestras acciones; por eso nos causa depresión. Además, el uso de la inteligencia puede tener consecuencias anti-sociales, cuando el individuo se preocupa sólo consigo mismo, actitud contraria a la intención de la naturaleza.

La función fabuladora surge, entonces, como una especie de antídoto natural para minimizar los riesgos que corre el ser humano al desarrollar la inteligencia. Así, "la religión debe remediar, en los seres dotados de reflexión, un posible déficit de apego a la vida" 28 . Del punto de vista de la religión estática, el hombre es el único animal cuya acción es incierta: vacila, elabora proyectos con la esperanza de tener éxito y el miedo a fracasar; puede enfermarse, sabe que va a morir y además tiene intereses egoístas. La naturaleza, sin embargo, tuvo que tomar ciertas precauciones para restaurar el orden de forma automática; lo hizo a través de la función fabuladora, destinada a desarrollar la religión natural: "una reacción defensiva de la naturaleza contra lo que podría ser deprimente para el individuo, y disolvente para la sociedad, en el ejercicio de la inteligencia"29.

Bergson nos ofrece una segunda solución, del punto de vista de la religión dinámica. La experiencia mística no es una producción imaginaria de fábula (como era el caso de la religión estática), sino un contacto vivido - por tanto, real- "con el principio de la naturaleza" ${ }^{30}$. La confianza que la religión estática le había dado al hombre sería transfigurada en las almas místicas, generando otro tipo de apego a la vida, ya que el "contacto místico" es una coincidencia parcial con el movimiento vital, impulso creador de la corriente evoluti$\mathrm{va}^{31}$. Pero de ese tema -el misticismo- nos ocuparemos en un próximo trabajo.*

\section{Bibliografía}

Bergson, H., Les deux sources de la morale et de la religion, PUF, Paris, 1932.

--------------, L'évolution créatrice, PUF, Paris, 1907.

Frazer, J. G., Le Rameau d'or. Une étude sur la magie et la religión, Reinwald, Paris, 1903.

Waterlot, G., Bergson et la religion. Nouvelles perspectives sur "Les deux sources de la morale et de la religion”. Paris, PUF, 2008.

Worms, F., Bergson ou les deux sens de la vie, PUF, Paris, 2004.

28 Ibid., p. 223.

29 Ibid., p. 217.

$30 \quad$ Ibid., p. 227.

31 "Como el hierro por el fuego que lo incandesce. Su apego a la vida sería de ahí en adelante su inseparabilidad de ese principio, alegría en la alegría, amor de lo que es sólo amor” (Ibid., pp. 224-225).

*Artículo recibido: 29 de junio de 2012. Aceptado: 20 de julio de 2012. 